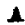

\section{HINT FOR PHYSIOLOGISTS.}

\section{To the Editor of THE Lancet.}

Srr,-I cannot resist from commilting to paper, and forwarding for circulation to your popular journal, the following suggestion to those who have time, inclination, and ability, for physiological experiments, on the subject of the circulation of the blood, and theory of inflammation. It occurred to my mind about five years ago while engaged in microscopical observation with Mr. Cuthbert ; and I communicated it last year to Mr. Varley, the eminent artist and ingenious and enthusiastic microscopist, while he was employed in exhibiting the circulation of the blood in the web of the frog's foot, at one of the evening scientific assemblies at Kensington Palace. I again repeated the suggestion this year to the same gentleman, and now that the magnificent power of light from Lieutenant Drummond's apparatus has been brought to bear on the microscope, so as to render the observations both easier and more evident, I cannot belp thinking that the "Hint for Physiologists" to which I allude, might be readily and successfully adopted, and put into execution.

"Expose the web of a frog in the usual manner, under the glass of the gas microscope, so as to exhibit the circulation of the blood. The phenomenon is seen most beautifully and distinctly. The two torrents, running in divers directions, and the globular structure of the fluid, are seen at one and the same time following the even course of their way. Let now the experiment be made of irritating with a sharp needle the web on any one point, and watch the result, whether and how the even course of the circulating fluid be disturbed-whether disturbed immediately or not-whether the current be retarded in one way and quickened in another-whether the glubular molecules congregate and are arrested, as around a centre, near the point of irritation - whether the form of the molecules is not then altered or modified - whether, in fact, from teing globular, they do not become polygonal-and whether it be not probable, that inflammation, and if so, subsequent febrile action, be not the result of polygonal globules or molecules so produced, circuiat. ing through the vascular system?" Rideat qui sapit. I have the honour to be, Your obedient servant,

A. B. Granville, M.D.

Grafton street, 21st February.
MEDICAI SOCIETY OF GENERAT. PRACTITIONERS OF SOUTHWARK AND ITS VICINITY.

\section{To the Editor of The LanceT.}

SIR,-I am directed by the General Medi. cal Practitioners Society of Southwark and its Vicinity, to forward to you the following resolutions passed at their last meeting. Relying upon your known liberality and consistent support of that branch of the profession for its early insertion in your valuable Journal, I am, Sir.

Your obedient servant, J. Cox, Hon. Sec.

11, Lambeth Walk, Feb. 19, 1833.

\section{Friday, February 15 th, 1333.}

W. R. Harrison, Esq., in the Chair.

The secretary congratulated the Society upon its rapid progress, the increase of its members, and the ample funds now in the hands of the treasurer, which he considered to be quite sufficient to carry into effect all the objects for which the Society was formed. After some other business had been gone through, one of the members produced the Medical and Surgical Journal for the 9th inst., the "leading article" of which was severely commented upon, and the following resolution proposed and carried unanimously :-

Resolved,-“" 'That No. 54 of The London Medical and Surgical Journal, which contains an infamous and splenetic attack upon general practitioners, be burnt, and that in future no more of that periodical shall be allowed to be brought into this Society."

Resolved,-- "That the secretary be re. quested to forward to the Editor of THE LANCET the heads of this evening's discussion, and a copy of the resolution expressive of the contempt of this Society for the disgraceful article reflecting upon general practitioners as a body, contained in The London Medical and Surgical Journal for the 9th inst."-Carried unanimously.

The journal was burnt in due form by the chairman.

An interesting discussion then took place on the subject of small-pox, Mr. Evass having inquired of the members present, how far in their minds vaccination was to be considered as a preventive of small-pox, he (Mr. Evans) having been called to numerous cases after vaccination.*

* We do not give the discussion which ensued, and in which Messrs. Hooper, Ratty, Howell, Fales, Cox, Brady, and Shrimshire, took part, the opinons being contradictory, and very the question left too dosbtful, to render its publication advantageous.ED. L. 
FUNGUS HEMATODES OF THE HEAD.

Mr. Cox then related the particulars of a case of fungus hæmatodes which had terminated fatally under the care of Mr. Davis, of York Town, Blackwater, and presented to the inspection of the members the drawings taken at the post-mortem examination, showing the condition of the brain at the time of death :-

John Banbury, footman in a gentleman's family, aged 23 years, was admitted into Guy's Hospital, March 16th, 1832, under the care of Mr. Morgan. He was of sallow complexion, but had previously enjoyed good health; had never experienced any injury of the head, except a slight scalp wound. More than fifteen years ago he first felt a degree of tenderness over the in. ferior-posterior angle of the left parietal bone, and had occasional shiverings, yet was free from headach, and enjoyed good general health. Three months from the date of his entrance at the hospital, a small moveable tumour appeared on the parietal bone, causing a sharp pain. A month after that, when it was of the size of a walnut, this tumour was opened, and some bloody serum escaped. This operation was twice afterwards repeated, and, on the last occasion, the bare bone was felt with a probe. On admission to the hospital, there was a tumour above and behind the left ear, of the size of half an orange, with a broad base, having the surface divided into three lobulated cysts, one of them more prominent, red, and tender, than the others. The tumour was very elastic, and at times was attended by much aching pain-so severe inderd as to prevent sleep. A slight deafness also $w$ as experienced, and the sight of the left eye was occasionally impaired.

On the 26th March, ten days after admission to the hospital, the dimness of sight and pain in the head having increased, leeches were applied to the tumour, with much relief of the symptoms, and a small quantity of opium was given, which procured sieep.

April 3. The surface was much inflamed and tender.

12. The disease extended so as to reacb the upper part of the ear and raise it from the scalp ; less pain was felt, but an increase of deafness supervened.

14. Ulceration was completed in the night, and about half a pint of bloody serum escaped from a small opening. Several cervical glands were enlarged.

Miay 10. The tumour had by this time acquired a considerable size, being nearly as large as half the head, and having the base considerably extended.

June. The patient left the hospital, as his parents were anxious that he sliould be brought home, for the purpose of piacing him in the hands of an unqualified practitioner.* When on his journey, a large ab. scess burst, in consequence, as they sup. pose, of the jolting of the wagon, and gave issue to a great quantity of highly offensive fluid, mixed with blood. He had previously suffered a good deal of pain, but as soon as the discharge took place he obtained relief. The person into whose hands he fell used powerful escharotics, the application of which always produced excruciating pain, and greatly accelerated the ulceration. After the dismissal of the person, my friend Mr. Davis was called in, and he simply employed anodynes and soothing applications to the tumour, with an occasional aperient.

Anasarcous swellings arose in about a week after the patient left the hospital, and continued. His appetite was generally very good, sometimes ravenous. His urine was for the most part scanty, and he was troubled with fits of fainting, especially on raising his head from the pillow, if not well supported. The sight of the left eye became more impsired, particularly when the head was raised; the deafness somewhat increased. He remained sensible to the period of his dissolution, and would frequently converse with those around him. The discharge for two or three weeks previous to his death was very great, of a dark colour, mixed with bits of bone, and exceedingly offensive.

As the ulceration spread, the vessels of the head were laid open, and he died (no doubt from hemorrhaye) on the morning of the 22nd of August 183\%.

\section{Autopsy.}

No internal post-mortem examination took place. The plates exhibited, on a side view,-1. The superior boundary of the tumour. 2. A large and deep excavation, extending to the bones of the left side of the head, partly containing a thin dark corroding matter, ulcerating the surrounding substance of the tumour, and causing considerable caries of the bones. 3. The parietes of the tumour, very thick, and of the consistence of macerated cartilage. The internal solid portion of the tumour when cut into, had a greyish appearance, and exhibited a great number of white cross bands. 4. $\mathrm{Ab}$. scesses of various dimensions, containing a thin ichorous fluid. 5. An extensive ulceration from the bursting of a large abscess. 6. The external ear lifted up and thrown forward by the tumour, so that only the posterior margin of the ear was visible from the side. There was ce? ema of the face. A posterior view of the tumour showed the

* The term employed in the report is a libe!. Ej. I. 
suppurative excavation and the jagged/the knife. A mass of muscle, depending edges of the tumour more distinctly. The from the scapula, hung out of the vagina. surface whitish, smooth, and even in some He waited three or four hours, and then parts fluctuating to the touch, and in others turned the fotus, and after some little diffihard and indurated.

The inferior boundary of the tumour terminated at the lower edge of the occiput, and from which the lower portion hung loose over the neck. The tumour measured from the os frontis of the left side to the os parietalæ of the right side, eighteen inches; and from the centre of the head to the bottom of the tumour, ten inches. Its weight was estimated at about six pounds.

The Society afterwards adjourned to eight o'clock p.m. of Friday the 1st of March.

\section{LONDON MEDICAL SOCIETY.}

Monday, Feb. 25th, 1833.

Dr. Burne, President.

culty delivered the woman of a child, uni-

lacertus. Soon after the mother died. From

whatever cause the event had taken place,

he thought the circumstances such as to de-

mand an application from bim to the autho.

rities for a judicial inquiry into the facts.

But the reply from the sheriff, coroner, and

other parties, was, that they could not investigate the matter, unless he could lay before them a high medical opinion, that the operation of curting off an arm, before turn. ing, with a pig-killer's knife, or other instrumerit, was an unwarrantable proceeding, and contraty to the received rules of mid. wifery. The result was, that no legal proceeding was instituted, but the woman was buried, and the grave closed for ever upon the mutilated corpses.

The President. Does Dr. Hendley wish to know if such an operation is ever performed in this country? lt is not, of course, impossible, but that circumstances MIDTIFERY IN TRELAND.

Dr. HeNDLEY took the opportunity of making an inquiry as to the frequency in England of amputation of the arm in difficult labours, where that member has descended first, and presents an apparent obstacle to speedy delivery; grounded on the following case. A woman was taken in child-birth somewhere in the county of Waterford in Ireland, in the absence of a medical man. The rigit arm of the child came down, and after waiting some time for its return, and a birth after the usual manner, a midwife in attendance got a neighbouring pig-killer to sharpen his knife to the uttermost, and lend it to her to aid her in performing amputation. This she accomplished by introducing the keen-edged tool, dividing the muscles around the humerus, and then, while two other women held the patient by the shoulders, forcibly wrenching and tearing the bone from the scapula,-a separation which required, it seemed, the exertion of no less power than the unfortunate boot.hook case which occurred two or three years ago a few miles from I.ondon. By-and-by Dr. Hendley was sent for, when he found that an immense hemorrhage had ensued, but whether directly from the foetus or not he could not tell,-

Ur. Dendy. Was the blood arterial or venous? The Presidint. Do you think you could tell from that, Mr. Dendy?

Mr. Dendr. Yes, 1 think I could tell whether it came from the circulation in the foetus or straight from the mother. But was the motber cut at all by the midwife?)

as no post-mortem examination was allowed. might demand an amputation of the limb of an undelivered fotus.

The object of Dr. Hendley seemed to be obtained by a mere communication of the facts, and little more therefore was said on the subject. The moral of the case, however, is this, that had the Irish coroner been a medical man instead of a lawyer, the narrator of the facts would not have been sent back to search for the ignorantly and absurdly demanded proof required from him, but the dictates of humanity would have been instantly responded to, in the exposure and consequent probable punishment of the slaughterers engaged in the horrible transaction.

\section{LIVING HYDATIDS.}

At the conclusion of these remarks,

Mr. Stephens entered the room in some haste, to exhibit to the Society three or four hydatids which he lad procured in the caurse of the afternoon, affording the mem. bers an opportunity of personally witnessing the existence of life in these " imperfect animalcules," as Baillie terms them, though the hydatids shawn on this occasion will almost justify the employment of the less equivocal term " animal."

The Presidrnt immediately drew attention to the exhibition. "This is very interesting," he observed, "as it settles a point greatly in dispute. Here is a head as clearly as a head can be. Get a littlo warm water, and see if it will revive the movements."

Mr. STSPIIENs. "MIost probably it will certainly been inflicted on the mother with not; for, unfortunately, they are now ex. 